\title{
CORONA IN CAPITE. JUAN DE SALISBURY Y DANTE ALIGHIERI
}

\author{
Martín González Fernández \\ Universidad de Santiago de Compostela
}

\section{RESUMEN}

Examen de afinidades y diferencias en la filosofía de dos cualificados representantes del Humanismo del siglo XII y XIV, Juan de Salisbury y Dante Alighieri respectivamente, a partir de un estudio comparado del Policraticus y De Monarchia; a la luz del proceso de secularización de la cultura y pensamiento europeos a fines del Medievo.

Palabras clave: Juan de Salisbury, Dante Alighieri, Humanismo, feudalismo, burguesía, hierocracia, laico, realeza, sacerdocio, De Monarchia, Policraticus.

\begin{abstract}
Exam of affinities and differences in the philosophy, of them qualified representatives of the Humanism of the XII and XIV centuries, John of Salisbury and Dante Alighieri respectively, through a compared study of Policraticus and De Monarchia; to the light of the secularization process of the culture and european thoughts at the end of the Medieval Age.
\end{abstract}

Key words: John of Salisbury, Dante Alighieri, Humanism, feudalism, bourgeoisie, hierocracy, laicism, royalty, priesthood, De Monarchia, Policraticus.

«Hay dos géneros de cristianos. El primer género está dedicado al oficio divino y se consagra a la contemplación y al rezo; conviene que viva alejado del ruido del mundo; son los clérigos, aquellos que están consagrados a Dios. En griego, en efecto, 'cleros' significa 'suerte'; estos hombres son llamados clérigos porque han sido elegidos por la suerte. Dios los ha escogido a todos. Son reyes, pues ellos dominan y reinan sobre los otros por las virtudes. Su reino está en Dios. Se les marca o destaca con la tonsura [corona in capite]. La Iglesia Romana les da esta corona en señal del Reino [...]. Hay otra suerte de cristianos, los laicos. 'Laos' en efecto significa 'pueblo'. A éstos les está permitido poseer bienes temporales, pero solamente por las necesidades del uso. Nada es más miserable, en efecto, que menospreciar a Dios por el dinero. Están autorizados a casarse, a cultivar tierra, dirimir querellas mediante juicio, litigar, depositar ofrendas sobre el altar, pagar diezmos: asi pueden ser salvados, a condición de que eviten los vicios haciendo el bien» (Decretum, 1150, de Graciano, causa XIII, q. 1, c. 7).

\section{HUMANISMO MEDIEVAL Y RENACENTISTA}

Muchos nexos unen al príncipe del Renacimiento cultural del siglo XII, Juan de Salisbury (1110/1120-1180), y al pionero del Renacimiento y Humanismo que surge en Italia a comienzos del siglo XIV, Dante Alighieri (1265-1321), el autor de la primera Summa «civil» de la mo- 
dernidad, la Divina Comedia (poesía — «sacro poema», según su autor-, enciclopedismo, pero, ¿por qué no una épica de la nueva clase burguesa?). ${ }^{1}$

Comparten, en efecto, pasión por la cultura clásica y utilizan y acomodan, en ocasiones, un mismo material literario procedente de la Antigüedad. En ambos, por ejemplo, Virgilio y Ulises, guías y vigías de un tiempo perdido, renacerán para los nuevos tiempos. Pero nada prueba, de hecho, que Dante haya leído al saresberiense. ${ }^{2}$

La coincidencia, tal vez, no podría ir mucho más lejos, dado que, ideológicamente, son autores que se hallan en las antípodas, como lo prueba un elemental análisis comparativo —el que deseamos, esquemáticamente, presentar aquí- entre el Policraticus (1159) de Juan de Salisbury y el De Monarchia (1312) de Dante Alighieri. Un examen en perspectiva, además, que nos servirá para comprender mejor el proceso de «secularización» o «laicización» de la cultura que se vive en Europa, ligado obviamente a la irrupción de una nueva clase social, burguesía, que, más allá de modificar el escenario de la disputa académica sobre el principio de soberanía y autoridad, lleva la filosofía al lego y cuestiona la ideología de las tres funciones o de los tres órdenes, del imaginario y del poder, consagrada en la época medieval.

\section{LOS TRES ÓRDENES}

Como nos ha probado G. Duby en numerosos y documentados trabajos, en el Medievo, se impone, ya tempranamente, una «economía simbólica» de los tres órdenes: oratores, be-

1 Se ha hablado del «conservadurismo» del Dante, al menos de planteamiento, por defender la idea de «Imperio» en tiempos de emergentes «monarquías nacionales» (Hans Kelsen habla del ideal «reaccionario» de Dante: Cfr. Kelsen, H., Die Staatslehre des Dante Alighieri, Vienna, F. Deuticke, 1905, Caps. IX y X; manejamos Ia versión italiana de W. Sangiorgi y G. Meyer Vom Bruck, Bolonia, M. Boni Ed., 1974, p. 161). Este esquema es, a nuestro entender, y al de otros especialistas más cualificados que nosotros, extremadamente simplificador. Sus textos, en efecto, permiten otras lecturas y delatan otros «síntomas» ideológicos. Recordemos, por ejemplo, por mencionar tan solo uno de ellos, que el tema que se somete a debate en el Tratado IV de $l l$ Convivio, otro escrito filosófico capital del Dante, es el de la naturaleza de la «nobleza» (= «nobilitate» 0 «gentileza») y que, en el debate, la voz del Filósofo (= su «Aristóteles») desautoriza a la del Emperador (= Federico II de Suabia, rey de Sicilia y emperador de romanos, 1194-1250) («É gentileza dounqu'è vertute»; C., IV, iii, pp. 212 y sigs.). En los aparados iv y v de este Tratado IV, como se dirá en su momento, intercala Dante un resumen y anticipo del contenido de los dos primeros libros del De Monarchia. Para la cuestión de la presencia de una ideología burguesa: vid. Batkin, Leonid M., Dante e la societá italiana del' 300 , Bari, De Donato, 1970. La dialéctica entre lengua latina y lengua vulgar, capital en Dante, pudiera servir en realidad de metáfora de la lucha o ténsión intestina en el texto entre estas dos matrices ideológicas (Imperio, burguesía). En el presente trabajo se citará la obra de Dante por la ed. castellana: DANTE ALIGHIERI, El Convite. Monarquía. Disputa sobre el agua y la tierra, Pról. de C. Vasoli, trads. de J. L. Gutierrez García, L. Robles y L. Frayle, corregida y anotada por Miguel A. Granada, Barcelona, Círculo de Lectores, 1995; con las siguientes abreviaturas: $\mathrm{C}=1 l$ Convivio y $\mathrm{M}=$ De Monarchia, $\mathrm{n}^{\circ}$ de libro, capítulo y parágrafo. Para Juan de Salisbury, se cita por: JUAN DE SALISBURY, Policraticus. De las frivolidades de los cortesanos y las enseñanzas de los filósofos, ed. M. Á. Ladero, Madrid, Editora Nacional, 1984 (=P., libro, capítulo y página).

2 Cfr. Curtius, E. R., «Dante und das lateinische Mittelalten», Romanische Forschungen, LVII (1943), pp. 153-185; Pézard, A., «Du Policraticus à la Divine Comédie», Romania, LXX (1948), pp. 1-36 y 163-191; Renucci, P., Une source de Dante: le «Policraticus» de Jean de Salisbury, Paris, 1952 (imposible de encontrar hoy en día), y, Dante, disciple et juge du monde greco-latin, Paris, Les Belles Lettres, 1954 (que suponemos que recupera la tesis del trabajo anterior y sí hemos tenido ocasión de leer); Paparelli, G., Ideología e poesia di Dante, Firenze, Leo S. Olschki ed., 1975, pp. 231-232; Vasoli, C., «Introduzione [al Convivio]», en DANTE ALIGHIERI, Opera minori, a cura di Pier V. Mengaldo et al., Milano-Napoli, R. Ricciardi, 1988, t. I/1, p. XXVII; Otto saggi per Dante, Firenze, Le Lettere, 1995, Cap. IV, «L'immagine 'enciclopedica' del mondo nel Convivio», p. 89, o «Il Convivio di Dante e l'enciclopedismo medievale», en L'enciclopedismo medievale, a cura di M. Picone, Ravena, Longo ed., 1994, pp. 363-381. Se podrían citar otros estudios. Ninguno prueba, a nuestro entender, con la salvedad de las coincidencias (lugares comunes, evocaciones de personajes y hechos de la Antigüedad, símiles y metáforas, etc.), que Dante haya leído a Juan de Salisbury. Para este último autor: Cfr. Raña Dafonte, C. L., Juan de Salisbury (1110/20-1180), Madrid, Eds. del Orto, 1999; entre otros trabajos. 
llatores y laboratores; la que, por ejemplo, queda sentada doctrinalmente en el Poème au roi Robert [le Pieux] del obispo Aldaberon de Laón, hacia $1030 .^{3}$

Y si leemos con atención el Policraticus, observamos que Juan de Salisbury se ciñe estrictamente a este esquema, al margen de las luchas contemporáneas entre regnum y sacerdocium, Guerra de las Investiduras y Libelli de lite. Su descripción del orden socio-político, que se corresponde a las estructuras de la sociedad feudal, y que él mismo nos presenta casi como un «orden natural» de las cosas, se ajusta efectiva y estrictamente a este esquema ideológico trifuncional (que algunos, como es conocido, siguiendo a G. Dumèzil, remiten a la ideología trifuncional indoeuropea):

«El príncipe ocupa en la comunidad política el lugar de la cabeza y se halla sujeto solamente a Dios y a quienes en nombre de él hacen sus veces en la tierra, como en el cuerpo humano la misma cabeza tiene vida y es gobernada por el alma. El Senado ocupa el lugar del corazón, ya que de él proceden los comienzos de los actos buenos y malos. Los jueces y los gobernadores de las provincias reclaman para sí la misión de los ojos, los oídos y la lengua. Los oficiales y los soldados se corresponden con las manos. Los que asisten al príncipe de un modo estable, se asemejan a los costados. Los recaudadores e inspectores (no los que controlan las cárceles, sino los encargados del erario privado del príncipe) pueden ser comparados al vientre y los intestinos. Si éstos se congestionan por una desmesurada avidez y retienen con excesivo empeño lo que han acumulado, engendran innumerables enfermedades sin cura posible, hasta el punto de que esta dolencia pueda conllevar la destrucción de todo el cuerpo. Los agricultores se parecen a los pies, que se encuentran continuamente pegados al suelo. Para ellos es especialmente la atención de la cabeza, ya que tropiezan con muchas dificultades mientras pisan la tierra con el trabajo de su cuerpo, y merecen ser protegidos con tanta o más justa protección cuanto que mantienen de pie, sostienen y hacen moverse a todo el cuerpo. Deja sin esas piezas de los pies a cualquier cuerpo, por robusto que sea, y no podrá caminar por sus propias fuerzas, sino que intentará arrastrarse torpemente con las manos, sin conseguirlo y con gran fatiga, o sólo se podrá mover con el auxilio de las bestias» ( $P$., Libro V, Cap. 2, pp. 347-348). ${ }^{4}$

3 En especial: Duby, G., Les Trois ordres ou l'imaginaire du féodalisme, Paris, Gallimard, 1978 (1 $1^{\mathrm{a}}$ ed. castellano, Barcelona, Petrel, 1980; $2^{\mathrm{a}}$ ed.., Barcelona, Argot, 1983 y $3^{\mathrm{a}}$ ed., Madrid, Taurus, 1992).

4 Y tiene, también, su réplica en negativo: «Porque también una comunidad política de impíos tiene cabeza y miembros, y en sus instituciones civiles se esfuerzan por ser semejantes a una comunidad legítima. Pues la cabeza de tal comunidad, el tirano, es imagen del diablo; el espíritu son los herejes, los cismáticos, los sacerdotes sacrílegos y, para usar la terminología de Plutarco, los prefectos de la religión que luchan contra la ley de Dios; su corazón, los impíos consejeros, que constituyen como un Senado de iniquidad; sus ojos, sus oídos, lengua y su mano desarmada, los jueces, las leyes y los funcionarios injustos; su brazo armado, los soldados violentos, a los que Cicerón llama bandidos; sus pies, aquellos que se oponen al mandato del Señor y a las instituciones legítimas aún en los asuntos más insignificantes. Todas estas cosas pueden ser fácilmente corregidas por los respectivos superiores» $(P$., Libro VIII, Cap. 17, p. 718). La ideología se disfraza con la máscara de la Naturaleza al comparar el cuerpo o la comunidad política con «el orden natural de las abejas» (imagen tomada de Virgilio en larga cita: Virgilio, Geórgicas IV 3, 153-218) (Cfr. P., Libro VI, Cap. 21, pp. 471-473). Nos dirá en su relativa euforia estoica: «...que la vida civil imite a la Naturaleza, a la que muchísimas veces hemos mencionado como óptima norma conductora de la vida. De lo contrario, habrá que llamarla no sólo incivil, sino más bien bruta y bestial» ( $P$., Libro VI, Cap. 21, p. 471). El príncipe es una «cierta imagen de Dios» (utiliza la ambivalente metáfora del «sol» en otras ocasiones), aunque la legitimación provenga del sacerdocio. «Esta espada, pues, la recibe el príncipe de manos de la Iglesia, ya que ésta no tiene ninguna espada de sangre en absoluto. Posee, sin embargo, ésta, pero usa de ella a través de la mano del príncipe, a quien dio la potestad de la coacción corporal, reservándose para sí la potestad de lo espiritual en la persona de los pontífices. Es, pues, el príncipe ministro del sacerdocio y ejerce aquel aspecto de los sagrados oficios que parece indigno de las manos del sacerdocio. Porque todo oficio dependiente de las leyes sagradas es religioso y piadoso y tiene categoría inferior aquel que se ejerce en castigo de los delitos y representa de algún modo la imagen del verdugo» ( $P$., Libro IV, Cap. 3, pp. 309-310). La tesis de las «dos espadas», con esta orientación hierocrática, había sido depurada por Bernardo de Claraval. En este sentido, no duda en indicar su posición ideológica y política: «A mí me satisface -y lo hago con convicción - someter al poder mis devotos hombros; y no sólo 
Y es, precisamente, desde esta perspectiva, con las turbulentas circunstancias históricas y de relación entre Iglesia y principados seculares de fondo, desde la que, especialmente en el Libro VIII (pero con antecedentes en otros libros: Cap. 10 y 15 del Lib. III, por ejemplo), critica la figura del «tirano» y defiende el tan controvertido derecho al tiranicidio, apuesta subversiva, desde luego, pero dentro de un orden (en el Cap. 21 del Lib. VIII nos presentará como prototipo de «tirano secular» a «Juliano, el vil apóstata y miserable emperador», pero apuntando siempre al Emperador o al monarca inglés). Y también es desde esta misma perspectiva que concluye su crítica a las «enfermedades» de la Iglesia, centradas ahora (pero con carácter retrospectivo, en el orden del discurso, en relación a las críticas que anteriormente había ido vertiendo) en el peculiar «escarnio y maldecir» del «tirano eclesiástico», para él, compendio, causa real, metáfora y símbolo (sígnico aquî) de todas las demás desgracias de aquella. Son la razón, en última instancia, de que la Iglesia, según su propia expresión, se convierta en «una sinagoga de malhechores, una Iglesia de pecadores». La crítica al «tirano eclesiásțico», que no es otro que aquél que cede al poder secular, y atenta contra los intereses de su propia dignidad, se desarrolla en los Capítulos 17-23 de dicho libro.

«Pero los sacerdotes no deben indignarse conmigo si admito que también entre ellos puede haber tiranos [...]./ Pues no hay [en algunos prelados] ni un ápice de libertad para hacer frente a las potestades del mundo, ningún valor para proteger a la verdad en peligro; entre sus asuntos buscan la ganancia, en ninguno o en muy pocos, la salvación de las almas. Mientras tengan éxito en sus asuntos, mientras se realice el deseo de su ambición y avaricia, no se preocuparán por que no se realicen los planes de Jesucristo [...]./ pero a un ladrón la Iglesia no le debe dar más que castigo [...] / ahora casi todo el mundo desea ser obispo, y cuando lo ha conseguido, lo que desea es dedicarse al ocio [...]./ Te maravillarías de los recursos y, como se suele decir, de las riquezas de Creso, que tienen unos hombres que predican a Cristo pobre [...]./ Otros viven del Evangelio, pero sin practicarlo, y démonos por satisfechos si solo viven de él, pues hay quienes nadan en la abundancia a su costa [...]./ Pero aquellos que desea ardientemente ganancias despreciando todo lo que pertenece a Cristo, aunque no sueñen nada herético, ni dividan la Iglesia con polémicas, no son dignos del nombre ni del honor del pastor ni del asalariado [...]./ Esta página va más bien contra los que van sentados en blandos cojines, disputan sobre el ayuno en la saciedad y destruyen con sus obras lo que construyen con sus palabras [...]./ Si alguno me acusa de haber dicho aquí cosas demasiado duras, me perdonará fácilmente cuando haya leído los escritos de los Padres. Pues si un tirano secular está condenado por el derecho divino y humano, ¿quién pensará que un tirano sacerdotal debe ser amado y respetado?» (P., Libro VII, Cap. 17, pp. 718-725).

Pero, al respecto, no es ésta su última palabra, y coherente con su ideología, parece además que no debiera serlo. Así, tras mostrar las dificultades que tiene la propia jerarquía eclesiástica (Papa) para poner coto a estos desmanes en ese momento histórico, pese a sus competencias y esfuerzos, hace, primero, una defensa cerrada del instituto apostólico ( Pues es evidente que hay que venerar las huellas de los Apóstoles y que los que poseen sus sedes e imitan sus vidas deben ser honrados como padres y respetados como señores»; Cap. 17, p. 724) e indica, luego, que, pese a la corrupción en que puedan caer los ministros de la Iglesia, en especial los cómplices de los tiranos seculares y los mencionados «tiranos eclesiásticos», la dignidad eclesiástica se halla siempre fuera del alcance de la espada secular: «De todo lo cual re-

lo soporto, sino que me es agradable, en tanto en cuanto está sujeto a Dios y se adapta a su orden. De otro modo, si resiste a los mandatos divinos y me quisiera hacer participar en su-lucha antirreligiosa, libremente respondo que Dios debe ser preferido a cualquier hombre. Pues así como los miembros inferiores se adaptan a los superiores, así todos los miembros deben someterse a la cabeza de modo que la religión permanezca incólume» ( $P$., Libro VI, Cap. 25 , p. 482 ). 
sultará fácil ver que siempre fue permitido adular y embaucar a los tiranos, y que siempre fue honesto quitarles la vida, si no se les podía poner coto de otro modo [...] Sin embargo, contra el sacerdote, aunque sea un tirano, por reverencia al sacramento de que está investido, no es lícito usar materialmente la espada, a no ser que haya sido degradado por haber alzado su mano sangrienta contra la Iglesia de Dios» ( $P$., Libro VIII, Cap. 18, p. 731).

Por lo tanto, se redimensiona la economía simbólica de la ideología trifuncional medieval (en atención a los cambios en los juegos de interés y en la economía del poder), ${ }^{5}$ pero se mantiene el esquema básico (la estructura del poder), y sale reforzado. Llama la atención, por ejemplo, que, al hablar de los «condes palatinos», a los que cita por su nombre (Gaufredo de Magnavilla conde de Essex, Milo conde de Hertford, Arnulfo conde de Cestria, Alano conde de Richmond, Simon conde de Northampton, Giliberto conde de Pembroch, Guillermo de Salisbury, Roberto Marmion) o, incluso, a los últimos reyes ingleses (especialmente denigrado es el rey «intruso» Esteban de Blois), o a grandes cortesanos con Enrique II (por ejemplo, Eustaquio, el hijo del mencionado rey Esteban), más que atacarlos por los atropellos a las libertades y privilegios eclesiásticos, asunto que también toca apuntando indirectamente al rey, les reprocha el descuido de su función de «miles», algo ciertamente sintomático. Juan, por supuesto, del campesinado (laboratores) no habla, o lo hace con cierto desdén.

Todo el tratado político de Juan de Salisbury se halla recargado de elementos «hierocráticos» (monarquía universal, ideología papal del Imperio y concepción de la ratione peccati, «comunidad cristiana» y «emperador de los romanos», principio de inmunidad eclesiástica en relación a los poderes seculares y reales, concepto de vicariato de Cristo, monopolización papal de la Biblia, Donación de Constantino y otras «grandes falsificaciones», limitación o partición de funciones, las alegorías del sol y la luna, etc.) y, además, a través de una presumible «falsificación laica», la Institutio Trajanii, condensa simbólicamente dicha ideología en la metáfora de la relación «cuerpo» y «alma». Esta metáfora, citada centenares de veces en el periodo medieval para demostrar la inferioridad de los laicos y la superioridad del clero (a mediados del siglo XI el cardenal Humbert la empleaba para subrayar que «los reyes constituían el brazo armado del clero, mientras que el clero equivalía a los ojos de toda la Iglesia y era quien sabía lo que debía hacerse»), como ha indicado Walter Ullmann, tenía un sentido muy preciso en el contexto ideológico «hierocrático» de madurez:

«Frente a estas antítesis no debemos dejarnos engañar por la pura alegoría. El uso metafórico de la alusión al alma y al cuerpo quiere expresar lo siguiente: dado que la fe en Cristo era el lazo que unía a toda la Iglesia, y puesto que la exposición de esta fe era tarea del clero, la misma ley, como regulador externo de la sociedad, debería basarse en esta fe. Fe y ley guardaban entre sí una relación de causa y efecto. El alma era en la alegoría ni más ni menos que la pura idea de derecho y la ley, la idea cristiana no contaminada de la recta manera de vivir. Qué específica acción legal o legislativa requería la fe debía ser decidido tan sólo por aquellos que tenían ojos para ver, el clero. Expresado de otro modo: puesto que toda ley debía materializar la idea de justicia, y dado que la justicia era uno de los elementos esenciales de la fe cristiana, el 'alma' en esta alegoría correspondía a la idea cristiana de justicia. Apenas puede dudarse de que esta concepción correspondía a la idea medieval del 'gobierno de la ley' y manifestaba la idea de la supremacía de la ley. Puesto que se decía que la comunidad de los creyentes tan sólo podía mantenerse unida por medio de la ley basada en a justicia (cristiana), que exterioriza a fe y refleja la concepción teleológica, se consideraba que la ley constituía el medio ade-

5 La escisión del «discurso del poder» y la «cultura oficial» en un momento histórico dado, su fragmentación y consiguiente debilitación, como ocurre en el siglo XII (la Guerra de la Investiduras, los Libelli de lite, la pugna entre los emergentes partidos güelfo y gibelino, etc.) explicaría, por ejemplo, la excepcional explosión y expansión simbólica (polisémica) del goliardismo (grotesco, carnavalesco). 
cuado merced al cual la comunidad cristiana cumplía con su objetivo final.En resumen, la ley era el alma que gobernaba el cuerpo de la comunidad de los cristianos. El legalismo de la Edad Media y en especial el de la forma hierocrática de gobierno hallan plena explicación. Se decía a menudo que tan sólo por medio de la ley podía un cuerpo público vivir, desarrollarse y alcanzar su finalidad. Según la concepción hierocrática, el rey estaba sujeto a normas sacerdotales, partiendo de la base de que no se hallaba lo bastante cualificado para dictar leyes que afectasen a la estructura básica de la sociedad cristiana. En esencia, esta concepción del alma y de cuerpo expresaba sencillamente la idea del gobierno de un cuerpo público y corporativo por medio de la ley». ${ }^{6}$

La «crisis» (de crecimiento) del discurso hierocrático, precisamente en el momento histórico de su emergencia y mayor pujanza (recordemos que la doctrina gelasiana - Gelasio I, Papa entre 492 y 496 - de los «dos poderes cooperantes», sancionada por la canonística reformista gregoriana - Gregorio VII, Papa entre1075 y 1085 -, es ahora desplazada hacia la idea de la «subordinación»), queda perfectamente reflejada en el Policraticus: no se daban todavía las condiciones necesarias, y no ocurrirá hasta la época de Dante, para que naciese «una ideología laica de la realeza». ${ }^{7}$

\section{CLÉRIGOS Y LAICOS: TEOLOGÍA-POLÍTICA Y FILOSOFÍA CIVIL}

Las circunstancias, históricas y personales, de Dante son ya diferentes. Dante es, en primer lugar, un laico que se mueve al margen de las Universidades medievales, pero que, hasta cierto punto, viene a ser un curioso y aventajado hijo de éstas. Luego, es alguien que reflexiona, filosóficamente, al margen de la teología: explota el legado de la «filosofía práctica» de Aristóteles y las encontradas lecturas que de él se habían hecho hasta entonces, y por entonces. Sus alegatos contra la teología-política propiciada por la Iglesia en el Medievo (doctrinas hierocráticas) le convierten pronto en enemigo y en un autor «maldito» para ésta. ${ }^{8}$ En él, se pasará de una «sacralización» a una «naturalización» del orden socio-político. Nos hallamos, pues,

6 Ullmann, W., Historia del pensamiento politico en la Edad Media, Barcelona, Ariel, 1999, $4^{\text {a }}$ reed., pp. 9899 (ed. original inglesa, 1965). Vid. sobre este punto: Raña Dafonte, C. L., «La dimensión práctica de la filosofía según Juan de Salisbury» (en este mismo Libro-Homenaje). El sistema papal hierocrático, como indica W. Ulmann, si algo dejó del todo claro fue, sin duda, «la estrecha relación entre ley y fe». Para Juan, también, «la plena función de la ley es religiosa y sagrada» y, en este sentido, no existe en él distinción «entre la teología y la política» (vid. Ullmann, W., Ibid., p. 118).

7 Algunas razones las ha apuntado ya el propio W. Ullmann: «El desarrollo del pensamiento político en la Edad Media se vio fuertemente condicionado por el predominio del elemento eclesiástico: éste contaba con un instrumental, una literatura, unas fuentes a su disposición. ¿Qué otro sector social podía haber contado con semejantes ventajas?» (Ullmann, W., Ibid., p. 88). La interpretación de un laico de la Biblia, como será el caso de Dante, resultaría grotesca e insólita en la época de Juan de Salisbury. En efecto, muchos obstáculos (teoría descendente del poder, ideas cristocéntricas, adhesión de los reyes cristianos a un sistema teocrático, etc.) impedirán, por siglos, dicha emergencia (si bien es cierto que, en el Medievo, la función o condición teocrática del rey era compensada, de hecho, con su función o condición feudal). Los problemas o dificultades del sistema teocrático regio (=reyes «por la gracia de Dios»), en especial cuando queda subordinado o funciona en la órbita del discurso hierocrático papal, quedan patentes ya en el análisis realizado por Juan de Salisbury: «Puesto que [el tirano] era el azote del pueblo cristiano, Juan de Salisbury aseguraba que podía ser muerto por sus súbditos, aunque en otro pasaje recomendaba que se rezase por la conversión del tirano. Ambas recomendaciones -el tiranicidio y las plegarias- son claros indicios de los problemas que la figura del rey teocrático suscitaba en pensadores del calibre de Juan de Salisbury. En la medida en que el rey era la fuente de la ley y en que la 'voluntad del príncipe' proporcionaba a las leyes su carácter vinculable, no existía ningún recurso constitucional para derrocar al tirano dentro de la ley. El recurso a la fuerza o a las plegarias equivalía a la involuntaria admisión de los defectos del sistema teocrático» (Ullmann, W., Ibid., p. 119).

8 Todo ello se traduce en la inclusión de su obra, especialmente el texto que analizamos, en los Índices Inquisitoriales, ya en el siglo XVI (1564); el De Monarchia permanece en el Índice Romano hasta 1881. 
ante un proceso inverso al de Juan de Salisbury. Estamos ya cerca, por decirlo así, de la concepción de la ley, no como «don de Dios», sino como «ojo compuesto de muchos ojos»; del principio de disolución -en teoría, claro- de la noción de «súbdito» y de la aparición de la de «ciudadano», donde ya no existe diferencia, ni de orden, ni de naturaleza, ni de función, entre laico y clérigo; del discernimiento y separación radical de dos cuerpos en la realidad social histórica, el «Cuerpo Místico» de Cristo y el «cuerpo natural político»; de la emergencia de un discurso ascendente del poder, que afectará - - siempre en teoría — tanto al poder civil como al eclesiástico, concretado en una rudimentaria ideología de la «soberanía del pueblo» (Marsilio de Padua, Bartolo, etc.); gérmenes teóricos que, por supuesto, permanecerán todavía hibernados por siglos.

La huella de Aristóteles en el De Monarchia (1312) del Dante es clara. Nos parece, en todo caso, que es más el «Aristóteles» de Il Comentatore (C. IV, xiii, 8, p. 248), Averroes, a quien se cita explícitamente en el texto, aunque redimensionado, ${ }^{9}$ que el de Santo Tomás, a quien no se cita pero que sí tiene en mente, el que anima este endiablado instrumento de teoría, polémica, y aún publicística, política ${ }^{10}$; que encontró réplicas, fulminantes, de inmediato (Guido

9 De «averroísmo político», a propósito del Dante, por ejemplo, ha hablado Bruno Nardi. Corregido, pero ratificado y ampliando la base de la argumentación, por: Imbach, Ruedi, Dante, la philosophie et les lä̈cs, Fribourg (Suisse)-Paris, Eds. Université de Fribourg-Eds. du Cerf, 1996 Chap. V, «Dante et a philosophie», especialmente pp. 141-148, y Chap. VI, «La dimension politique de l'intellecte humain chez Dante», Ibid., pp. 173-196. Entre los estudiosos de habla hispana no parece haber acuerdo: Cfr. Truyol y Serra, A., Dante y Campanella. Dos visiones de una sociedad, Madrid, Tecnos, 1968, p. 67, que insiste en el «influjo averroísta», y Gómez Robledo, A., Dante Alighieri, I. Las obras menores, México, Universidad Autónoma de México, 1975, p. 129, que le resta importancia. Dante remonta, por así decir, la concepción «atomística» del «Intelecto Único» de los averroístas. «Es evidente que Dante tomó la noción del 'intelecto universal' de Averroes, al que por otra parte citaba abiertamente; pero esta noción, para Dante, tenía un significado distinto que para el averroísmo. Los averroístas soñaban con un intelecto terreno separado que debía ser actualizado en, o por, el filósofo, el individuo: sin embargo, Dante pensaba en colectivo. Tenía in mente un intelecto terreno inmanente que no se hallaba separado de sus componentes humanos individuales, aunque trascendía a cada uno de ellos, y sólo podía ser actualizado plenamente por una universitas que actuase como 'un hombre', como un individuo colectivo. A pesar de todo ello, es innegable que el concepto de Dante tiene un cierto olor a heterodoxia, especialmente por el hecho de que el propio Dante citaba y pensaba en Averroes cuando trataba este tema. Por ello, aunque de modo superficial, su adversario Guido Vernani tenía razón cuando consideraba la doctrina filosófica del poeta como un pessimus error. Sólo que el pessimus error no se fundamentaba meramente en la doctrina del intelecto colectivo. Vernani - correctamente desde el punto de vista convencionalpartía del anima intellectiva, el alma intelectual, implicando con ello la tradicional unidad entre el alma y el intelecto; y, desde esta premisa, el intelecto colectivo de Dante hubiese también implicado un 'alma colectiva', o alma terrena, negándosele, por ende, el alma individual al hombre y la posibilidad de su perfección individual y propia redención. Sin embargo, Dante había separado, por así decir, el intelecto del alma y las virtutes intellectuales de las virtutes infusae; y, quizá exagerando, se podría sugerir la hipótesis de que, en cuanto al intelecto Dante visualizaba una perfección predominantemente colectiva, mientras que en cuanto al alma preveía la tradicional perfección individual» (Kantarowicz, Ernst H., Los dos cuerpos del rey. Un estudio de teología política medieval, trad. S. Aikin Araluce y R. Blázquez Godoy Madrid, Alianza Ed., 1985, p. 443). Nos recuerda este investigador que muchas de las «condenaciones» parisinas de 1277 contra los averroístas, especialmente las relacionadas con la «santidad intelectual del filósofo» (que Dante trasladará, ahora, a toda la «comunidad universal» de hombres, suerte de militante y «secular cuerpo místico») -noción que renace de la operación «quirúrgica» a la que nuestro autor somete la teología-política medieval separando de nuevo las cuatro virtudes cardinales clásico-paganas (Prudencia, Fortaleza, Templanza y Justicia) de las tres virtudes teologales cristianas (Fe, Esperanza y Caridad)—, podrían ser fácilmente aplicadas a Dante. Por lo demás, la reivindicación radical de la «autonomía» o «autarquía» de la razón (Filosofía = Donna Gentile, Beatrice) y el primado de la razón práctica (=el «entendimiento práctico», Lib. I del $D e$ Monarchia, M. I, 8-9, p. 313; Ética= Cielo Cristalino, por encima de la física y metafísica [Cielo de las Estrellas Fijas, el primer movido] y por debajo de la Teología [el impasible y lejano, inmóvil, Empíreo], en el Tratado II del Il Convivio, C. II, pp. 85-137), son trazos del «averroísmo latino» que veremos renacer, dos siglos después, por ejemplo, en Pietro Pompanazzi.

10 No compartimos aquí, con todos los respetos, la interpretación de W. Ullmann. Este autor defiende que la distinción y articulación -en el Libro III del texto de Dante- entre dos órdenes de cosas, el natural y el sobrenatural, la civilitas y la christianitas, tal y como se observa en su interpretación desmitificadora de la alegoría del «sol y luna» o en el enigmático pasaje final del escrito («El César, pues, debe guardar reverencia a Pedro, como el hijo 
Vernani de Rimini, hará circular una muy virulenta y ácida De reprobatione Monarchie composite a Dante, h. 1327-1329). Tomás de Aquino y Siger de Bravante, o los averroístas, en todo caso, convivirán en forzosa armonía en el Paraíso dantesco. Es más, allí, como es de sobra conocido, se pone en boca de Tomás de Aquino el elogio de la «luce eterna di Sigieri» (Paraíso, $X, 136)$.

\section{El paraíso terrenal}

"Hay dos cosas, Augusto emperador, por las que este mundo es gobernado de modo especial: la sagrada autoridad de los pontífices y la potestad regia; en ellas, la carga que pesa sobre los sacerdotes es mayor, porque en el día del juicio divino deben dar cuenta al Señor también por los mismos reyes. Sabes, hijo clementísimo, que, aunque presidas al género humano por tu rango, debes inclinar la cabeza devotamente ante quienes administran las cosas divinas [...] y conoces bien que no debes presidir el orden de la religión, sino someterte a él» (Gelasio I, Papa entre 494-496, en Carta al emperador Anastasio I, a proposito del cisma de Acacio; Ep. 8, en PL 49, 42).

En el apartado ii del Libro I del De Monarchia, nos traza Dante un plan de trabajo, que cumplirá con tanto rigor lógico como pasión política. «Hay que ver, en primer lugar, qué se entiende por 'monarquía temporal', es decir, cuál sea su modelo ideal. Pues la 'monarquía temporal', llamada también 'imperio', es aquél principado único que está sobre todos los demás en el tiempo o en las cosas medidas por el tiempo. Tres cuestiones principales se plantean al respecto. En primer lugar se pregunta si la monarquía es necesaria para el bien del mundo; en segundo lugar, si el pueblo romano se atribuyó conforme a derecho a sí mismo el gobierno monárquico; $\mathrm{y}$, en tercer lugar, si la autoridad del monarca depende de Dios directamente o de un tercero, ministro o vicario suyo» (M. I, ii, 1-3, p. 310). Aquí nos interesa, especialmente, el Libro III. Digamos, si acaso, que las ideas centrales de los dos primeros libros se encuentran expuestas ya, en forma embrionaria y en vulgar, en el Tratado IV de $I l$ Convivio, texto en el que precisamente el «Filósofo» ofrece los instrumentos, los medios, para degustar el «pan de los ángeles». ${ }^{11}$ «El fundamento radical de la majestad imperial es en realidad la necesidad de la sociabilidad humana, que está ordenada a un fin, a saber: la vida feliz». La majestad imperial encarnará el principio de autoridad, en cuanto árbitro y potencia «reguladora o regente», que garantiza la paz universal y la realización de tal finalidad: «para la perfección de la universal religión de la especie humana es menester que haya quién, a manera de piloto, considerando las diversas condiciones del mundo en los diversos y necesarios oficios, tenga por entero el universal e irrefutable cargo de mandar». Tal oficio recibe el nombre de «imperio»y, de él, de su ley, toman los demás poderes seculares su «fuerza y autoridad». A los romanos les

primogénito debe reverenciar a su padre: para que iluminado con la luz de la gracia paterna, irradie con mayor esplendor sobre el orbe de la tierra, a cuya cabeza ha sido puesto por sólo Aquel que es el único gobernador de todas las cosas espirituales y temporales», M. III, xv, 18, p. 400), responde a una aplicación práctica de la tesis tomista, en su peculiar lectura de Aristóteles, de que «la gracia no contradice sino que perfecciona la naturaleza (gratia non tollit naturam sed perficit)»; fórmula de la que, por cierto, existía ya un precedente, aunque aislado y poco fértil en su momento, en la afirmación de Juan de Salisbury de que «la naturaleza es fecundada por la gracia (naturam fecundat gratia)» (Metalogicum, I, 1) (Cfr. Ullmann, W., Ibid., pp. 183-184). Tal vez debiéramos deslindar mejor en el escrito, creemos, el plano teórico del meramente retórico. Nos ocuparemos de ello más adelante.

$11 \mathrm{El}$ «pan de avena» del comentario en vulgar de unos versos suyos que encabezan cada libro del texto, frente al «pan de trigo» de los comentarios en latín, se trasmuta aquí en «pan de cebada» al servicio de un auditorio laico más amplio: «Éste será el pan de cebada con el cual se saciarán miles, y a mi me sobrarán las espuertas llenas. Ésta será una luz nueva, un nuevo sol que se levantará allí donde el usual se pone y dará luz a aquellos que están en tinieblas y en oscuridad, porque el sol acostumbrado no los ilumina» (C. I, xiii, pp. 83-84). Dante invita así a todos, sin distinción de condición (clérigos o laicos), sin exclusión, al banquete del «pan de los ángeles» (=sabiduría filosófico-teológica). 
otorgó y garantizó la Providencia divina ese «imperio sin fin» invocado ya por Virgilio en la Eneida (I, 278-279) (C. IV, iv, pp. 213-216). La fuerza sólo ha sido una «causa instrumental» en la instauración de tal dignidad y privilegio. «El nacimiento de la ciudad santa [Roma], que fue contemporáneo de la raíz de la progenie de María, es prueba suficientemente clara de la elección divina del imperio romano» (C. IV, v, p. 218). ${ }^{12}$ Trazos libres y sueltos de un lienzo elaborado más técnicamente, desde el punto de vista filosófico (con invocación de Averroes incluida), en los dos libros iniciales del De Monarchia. ${ }^{13}$

El De Monarchia, como era habitual en su autor, está redactado en forma de tríadas, reductibles siempre a un dualismo estructural. El tercer libro del texto reproduce, a la vez, el mismo esquema, tal vez de una forma más pronunciada. Así, a la pregunta inicial: «y, en tercer lugar, si la autoridad del monarca depende de Dios directamente o de un tercero, ministro o vicario suyo», o sea si se debe hablar de coordinación o de subordinación jerárquica entre Papa y Emperador, procederá el autor: $1^{\circ}$ ) en las dos primeras partes del libro, de modo crítico, mediante la aplicación de la lógica, el sentido común y la hermenéutica (casi mejor, «semiología», término de matriz teórica estoíca: Dante es tan aficionado como Juan a distinguir los diferentes estratos, grados y niveles de interpretación de las realidades lingüísticas) ${ }^{14}$, se ocupará de rebatir la «retórica hierocrática» de la plenitudo potestatis (Sagradas Escrituras las dos luminarias, Leví y Judá, la ofrenda de los Magos, «atar y desatar», las «dos espadas» [M., III, iv-ix] - y tradiciones y derecho - la donación de Constantino [= «la usurpación del derecho no crea derecho», M., III, x], en especial-e, incluso, razón: «Siendo pues, el papa y el emperador lo que son por ciertas relaciones, es decir, por el papado y por el imperio, que son, en efecto, verdaderas, una en la esfera de la paternidad y otra en la del dominio, es evidente que el papa y el emperador en cuanto tales, tienen que ser encuadrados en la categoría de relación y, consiguientemente, deben ser reducidos a un algo existente dentro de este género» [M. III, xi, 6, p. 390], siendo esta unidad el mismo Dios «en el que toda relación se une universalmente» $)^{15}$; y $2^{\circ}$ ) en la tercera parte, empleando ya la «vía corta», mostrando, por la razón y la filosofía, la necesidad de la coordinación, que no subordinación, de Papa y Emperador, como poderes derivados directamente de Dios. Los argumentos filosóficos se despliegan en los ca-

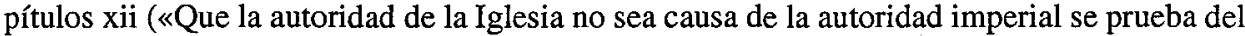
siguiente modo: cuando una cosa tiene su virtud sin la existencia o la virtud de otra, esta última no es causa de la virtud de la primera; ahora bien, el imperio tuvo toda su virtud sin la existencia y la virtud de la Iglesia; luego la Iglesia no es causa de la virtud del imperio y, consiguientemente, tampoco de su autoridad, pues su virtud y autoridad se identifican», M. III, xii, 3, p. 392), xiii (si la Iglesia tuviera la facultad de conferir la autoridad al príncipe romano, «o le vendrá de Dios, o de sí misma, o de otro emperador, o del consentimiento universal, o al menos de la mayoría»: Dante prueba que esto, por razón e historia, ni fue, ni pudo, ni puede

12 Para probar que la dignidad de imperio del pueblo romano - al «ungido» príncipe romano (de resultas de aplicar a él lo dicho por el Profeta en Salmos 2:1-3) —, es conforme a «derecho» no dudará en recurrir tanto al «testimonio y luz de la razón humana» (elementos históricos, filosóficos y jurídicos) como a «la iluminación de la autoridad divina», que, para este asunto, y para satisfacción del (nuestro y Nuevo) Poeta, se muestran concordes («Y, cuando las dos coinciden, es necesario que el cielo y la tierra den su asentimiento») (Cfr. M. II, i, 7, p. 336).

13 Para la estructura y detalles: RICCI, P. G., «Monarchia», Enciclopedia Dantesca, Roma, Istituto della Enciclopedia Italiana, 1984², Vol. III, pp. 993-1004.

14 Recordemos que es el propio Dante quien reivindica el carácter «polisémico» en y de sus textos (Cfr. C. II, i, pp. 89-91; y Carta a Cangrande della Scala, Ep. XIII, 20).

15 El argumento o principio filosófico de la «reducción del todo a la unidad», que toma Dante de varios escritos de Aristóteles en el Libro I del De Monarchia para reafirmar la necesidad de una monarquía o Imperio en lo temporal, había sido empleado por los defensores de las tesis hierocráticas, especialmente en el siglo XIII, «en conexión con el principio de la unidad sacramental de la Iglesia». Dante aplica a las dos supremas potestades dicho principio, el de la «reducción a la unidad», pero «introduciendo en lugar de la subordinación, su derivación desde un principio superior que las unifica: Dios, fuente primera y absoluta de todo poder» (Cfr. Vasoli, C., «Prólogo», op. cit., p. 38). 
ser así) y xiv (según la razón, aquello que es contrario a la naturaleza de una cosa no puede formar parte de sus facultades, ya que éstas siguen a la naturaleza de la cosa para la consecución de su propio fin: " ahora bien, la facultad de conferir autoridad a un reino de nuestra humanidad mortal es contraria a la naturaleza de la Iglesia; luego no está entre sus facultades», M. III, xiv, p. 395; si nos atenemos a las Sagradas Escrituras, el texto revelado).

La conclusión se fija en el capítulo o apartado xv. En efecto, si en estos tres breves capítulos previos, se ha probado, por vía negativa y «a modo de conveniencia», que «la autoridad del imperio depende inmediatamente de Dios», en el último la razón filosófica demuestra «palmariamente» que el monarca del mundo «está en relación inmediata con el príncipe del Universo, que es Dios», y no depende de la mediación del llamado «vicario de Dios», o sea el Papa, partiendo de un nuevo horizonte de reflexión.

«Por consiguiente, la inefable Providencia propuso al hombre dos fines a conseguir, a saber: la felicidad de la vida presente, que consiste en la actuación de sus propias facultades y se simboliza por el paraíso terrenal; y la felicidad de la vida eterna, que consiste en el gozo de la visión de Dios, a la que la propia virtud no puede ascender, si no es ayudada por la luz divina, felicidad ésta que nos es dado a entender como paraíso celestial [...] Por eso fue necesario al hombre tener un doble guía, de acuerdo con este doble fin, a saber: el sumo pontífice, que conduce al género humano a la vida eterna según la verdad revelada, y el emperador, que dirige el género humano a la felicidad temporal, según las enseñanzas filosóficas [...] Dios es el único que elige, Él es el único que confirma, pues no tiene superior [...] Resulta, pues, evidente que la autoridad desciende sobre el monarca temporal desde la fuente de la autoridad universal sin ningún intermedio; fuente que, única en la cumbre de su simplicidad, se derrama en múltiples cauces por la abundancia de su bondad» (M. III, xv, 1-18, p. 397-400).

La redacción de «E1 Purgatorio» de La Divina Comedia quedó terminada en 1312-1313; se trata de un texto prácticamente contemporáneo, algo posterior, al De Monarchia. Allí se pone en boca de Marco, según los críticos Marco Lombardo, cortesano de Venecia y amigo de Dante, un alegato a favor del İmperio y contra las pretensiones de plenitudo potestatis del Papado. Fija de algun modo, pues, la posición definitiva de Dante ante el problema. En el «discurso» de Marco, por cierto, se cuestiona la lectura tradicional, de origen agustiniano y alentada por los partidarios del hierocratismo a partir del siglo XI, que ve en el «poder», en el poder temporal, la expresión más nítida y manifiesta de la «caída», del «pecado», de la «corrupción». Y aunque el ataque a la Iglesia, y al Papado en concreto, es directo y frontal, incluso marcadamente virulento; lo interesante de la intervención de Marco es el cambio de plano en la teoría y reflexión política. Dejando a un lado, claro, las reconvenciones, por cierto unas alusiones críticas que sorprenden por su carácter de extrema obviedad, que se advierten en el pasaje en torno al averroísmo, o a ciertos aspectos del mismo.

«Un fuerte suspiro, que terminó en un ¡ay!, lanzó antes de contestarme, y después dijo [Marco]: 'Hermano, el mundo está ciego y tú vienes de allí. Vosotros, los que vivís, toda causa la hacéis depender del cielo, como si todo lo moviese él necesariamente. Si así fuese, estaría destruido en vosotros el libre albedrío y no sería justo que el bien proporcionase gozo, y el mal, dolor. El cielo inicia nuestros movimientos, no digo todos; pero, aunque lo dijese, luz se os ha dado para distinguir el bien del mal, y voluntad libre, que, si se fatiga en las primeras batallas en el cielo, después lo vence todo si se sustenta bien. A mayor fuerza y a mejor naturaleza estáis sujetos aunque libres; y ella cría en vosotros la mente, que no está bajo el influjo del cielo. Pero, si el mundo presente se extravía, en vosotros está la causa y en vosotros la debéis buscar, y yo te lo demostraré verdaderamente. Sale de Aquel que la acaricia antes de que exista, como a una niña que riendo y llorando parlotea, el alma sencilla, que no sabe nada, salvo que, movida por un deseo de goce, se inclina voluntariamente a todo lo que la regocija. Se inclina al placer de los bienes pequeños; aquí se engaña y detrás de ellos corre la guía o el freno no tuerce su pa- 
sión. De donde conviene establecer leyes como freno y conviene tener rey que discierna de la verdadera ciudad, al menos, la torre. Las leyes existen; pero ¿quién cuida de que se cumplan? Nadie, puesto que el pastor que a todos precede puede rumiar; pero no tiene la pezuña hendida, por lo cual la gente que ve a su guía sólo aspira a aquellos bienes de que ella está codiciosa, de ellos pace y no pide más. Bien puedes ver que en el mal gobierno está la razón que ha hecho al mundo culpable, y no en vuestra naturaleza corrompida. Solía Roma, que hizo bueno al mundo, tener dos soles, que uno y otro camino hacían ver: el del mundo, y el de Dios. El uno ha obscurecido al otro y se han unido la espada y el báculo; y cuando la una y el otro andan juntos, por fuerza han de ir las cosas mal, ya que, estando unidos, no se temen el uno al otro. Si no me crees fíjate en el fruto, que toda hierba se conoce por su semilla. En la tierra que riega el Po y el Adigio, solían encontrarse a cortesía y el valor antes de que Federico entrase en liza. Ahora puede tranquilamente pasar por allí cualquiera que hubiese dejado de hacerlo por vergüenza de hablar con los buenos o aproximarse a ellos. Bien es cierto que aun viven allí tres ancianos en los que reprende la antigua edad a la nueva y les parece que Dios tarda en llamarlos a mejor vida: Conrado de Palazzo [Conrado III, de Palazzo de Brescia], el buen Gerardo [Gerardo da Camino, llamado el Bueno] y Guido de Castel [Guido Roberti], a quien mejor llaman, a la francesa, el sencillo lombardo. Hoy la Iglesia de Roma, por confundir en sí dos gobiernos, ha caído en el fango y se ha manchado a sí misma y a sus poderes'..». (Purgatorio, XVI, 64-129). ${ }^{16}$

Así pues, de algún modo, pero ciertamente también para invertir su sentido, Dante vuelve a la concepción «diárquica» gelasiana del poder; concepción, por cierto, que tiene su origen en la Antiguiedad (potestad tribunicia, autoridad imperial; la «esfera de la paternidad y la del dominio», en Dante, M. III, xi, p. 390). ${ }^{17}$ Dos potestades (papal e imperial, coordinadas), dos paraísos (celestial y terrenal), dos tipos de virtudes (teologales, por un lado, y morales e intelectuales, por otro), dos tipos de documentos (Revelación y filosofía); pero única «monarquía» terrenal y «verdad» única.

El gobernante, el Emperador, es aquél «jinete que cabalga sobre la voluntad humana» general (C. IV, iv, 10; p. 234) con la brida y la espada de la «Razón escrita» (=el Derecho), como nos recuerda en $I l$ Convivio (exposición técnica y metodológicamente más platónica que aristotélica); es aquél que busca, algo más que consuelo y refugio, «luz», en las razones y argumentos de la Filosofía (= la sola Razón):

«Por lo cual, resumiendo todo lo dicho, queda claro el intento principal; es decir, que la autoridad del sumo filósofo de quien hablamos [Aristóteles] está llena de todo vigor. Y no contradice a la autoridad imperial, sino que aquélla sin ésta es peligrosa, y ésta sin aquélla es muy débil, no por sí misma, sino por el desorden de los pueblos, de forma que unidas ambas son muy útiles y muy eficaces. Por eso está escrito en el libro de la Sabiduría: 'Amad la luz de la sabiduría vosotros todos cuantos gobernáis los pueblos', es decir, únase la autoridad filosófica a la imperial para gobernar con perfección. ¡ Oh desgraciados los que hoy gobernáis! ¡Y más desgraciados aún los que hoy sois gobernados! Ninguna autoridad filos6fica se une a vuestros mandatos ni por el estudio personal ni por el consejo de otros, de tal manera que a todos se les pueden aplicar aquellas palabras del Eclesiastés: '¡Ay de ti, país, que tienes por rey a un niño y cuyos gobernantes banque-

16 Citamos La Divina Comedia por la versión de Nicolás González Ruiz: Cfr. DANTE ALIHIERI, Obras completas, Madrid, BAC, 1956, pp. 330-333.

17 El Papa Gelasio I (492-492): «con una distinción parecida a la que se daba en Roma entre la potestad tribunicia y la autoridad senatorial, Gelasio atribuye al emperador la potestas, el poder y los medios del Estado, mientras que reserva para la Iglesia la auctoritas, una preeminencia, de orden y dirección» (Barcala Muñoz, A., «La Edad

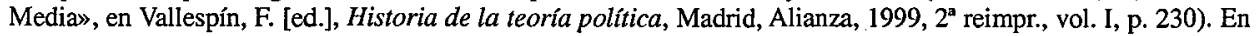
Gelasio I el concepto se halla en plena expansión; en Dante entra ya en «crisis», aunque tardará siglos aún en ser radicalmente cuestionado, como ya se apuntó. 
tean de mañana!'; y, en cambio, no hay pueblo al que se le pueda decir lo que sigue: 'Dichoso tú, país, que tienes por rey a un hombre noble y cuyos gobernantes comen a su tiempo para refección, mas no por francachelas'. ¡Prestad atención, enemigos de Dios, a los flancos, vosotros que habéis tomado la vara del gobierno de Italia! - y hablo a vosotros los reyes Carlos [Carlos el Cojo, rey de Nápoles, 1285-1309] y Federico [Federico II de Aragón, rey de Sicilia, 1296-1337], y a vosotros los demás príncipes y tiranos. ¡Mirad quién se sienta a vuestro lado para aconsejaros y contad el número de veces que durante el día os proponen vuestros consejeros el fin verdadero de la vida humana! Mejor os estaría volar bajo, como las golondrinas, que no, como buitres, dando vueltas altísimas sobre las cosas más viles» (C. IV, vi, 17-20, p. 224-225). ${ }^{18}$

Pero el officium de «razonar» no es privativo ya del Emperador o del intelectual, clérigo o laico, sino de cualquier «hombre libre», ya que le permite comprender la responsabilidad de ser, por emplear el lenguaje lacónico y abstracto del Libro I del De Monarchia, una «parte de un todo» (= «doble orden, esto es, el orden de las partes entre sí [el 'género humano' o la 'multitud humana', la Sociedad en definitiva] y el orden de las partes con relación a otra cosa que no es parte», en este caso, el Emperador). Cualquier «hombre libre», en definitiva, puede (debe) ser aquel «menor de los filósofos», título que Dante reclama para sí en su famosa «Disputa» sobre los elementos naturales (Quaestio de situ aquae et terrae,1320, Cap. xxiv).

\author{
Martín González Fernández \\ Departamento de Filosofía y Antropología Social \\ Facultad de Filosofía \\ Campus Universitario Sur \\ 15782 Santiago de Compostela
}

18 Mientras Juan de Salisbury habla de los «condes palatinos», aun mencionando nombres propios, como singularización y particularización del género, en este caso del estamento de la «nobleza»; Dante, por el contrario, cuando se refiere a Conrado III de Palazzo de Brescia, a Gerardo da Camino el Bueno o a Guido Roberti el sencillo Lombardo, y a tantos otros, por los que muestra admiración y respeto, especialmente en el gran retrato o fresco que hace de su tiempo en La Divina Comedia (1309, 1312-1313 y 1320), nos habla de los protagonistas de la «historia real», de los hacedores de los principados modernos, de la burguesía. El «tercer Estado» desbanca definitivamente la ideología estamental medieval. 